\title{
A Relação Semiótica entre a Linguagem Cartográfica e a Língua Brasileira de Sinais ${ }^{i}$
}

\author{
The Semiotic Relationship between Cartographic Language and Brazilian Sign Language
}

\author{
La Relación Semiótica entre el Lenguaje Cartográfico y la Lengua Brasileña de Señales
}

\author{
Tuane Telles Rodrigues ${ }^{1}$
}

\begin{abstract}
RESUMO: Sabemos que a Cartografia Escolar é fundamental no ensino de Geografia, possibilitando aos seus iniciados a materialização de diversas informações físico-sociais sobre um território. Contudo, ela não deve ser considerada uma simples ferramenta de espacialização, pois transcende a simples organização de dados e assume uma linguagem própria, capaz de comunicar algo sem a necessidade do uso de línguas orais, como o português. É neste contexto que ela se assemelha a língua brasileira de sinais (Libras), sendo passível de estabelecer a comunicação e a democratização de suas informações por meio da leitura visual. Com isso, objetivamos discutir a relação semiótica entre a Libras e a Cartografia e apresentar a versatilidade da linguagem cartográfica na comunicação de informações a alunos surdos, para assim contribuir com as estratégias de inclusão no ensino escolar. Para tanto, a metodologia utilizada consistiu na aplicação de uma oficina de alfabetização cartográfica em uma escola de educação especial em Santa Maria, RS/Brasil, onde pudemos trabalhar a leitura e interpretação das informações apresentadas nos mapas com os alunos surdos. Os resultados mostraram respostas positivas à premissa inicial de que a linguagem cartográfica é facilmente compreendida por alunos surdos, possibilitando de forma significativa a alfabetização cartográfica e, consequentemente, a compreensão dos conteúdos geográficos.
\end{abstract}

PALAVRAS-CHAVE: Relação semiótica. Ensino de Geografia. Libras.

ABSTRACT: We know that school cartography is fundamental in the teaching of Geography, enabling its initiates to materialize various physical and social information about a territory. However, it should not be considered a simple spatialization tool, since it transcends simple data organization and assumes its own language, capable of communicating something without the need of using oral languages, such as Portuguese. It is in this context that it resembles the Brazilian Language of Signals (Pounds), being able to establish communication and democratization of its information through visual reading. With this, we aim to discuss the semiotic relationship between Libras and cartography, and to present the versatility of the cartographic language in the communication of information to deaf students, and thus contribute to the strategies of inclusion in school education. The methodology used consisted in the application of a cartographic literacy workshop in a special education school in Santa Maria, RS / Brazil, where we were able to read and interpret the information presented on the maps with the deaf students. The results showed positive responses to the initial premise that the cartographic language is easily understood by deaf students, making possible the cartographic literacy, and consequently, the understanding of the geographic contents.

\footnotetext{
1 Universidade Federal de Santa Maria, Av. Roraima, 1000 - Camobi, Santa Maria - RS, 97105-900. tuanytel@hotmail.com.
} 
KEYWORDS: Semiotic relations. Geography teching. Libras.

RESUMEN: Sabemos que la cartografía escolar es fundamental en la enseñanza de Geografía, posibilitando a sus iniciados la materialización de diversas informaciones físico-sociales sobre un territorio. Sin embargo, no debe considerarse como una herramienta espacial sencilla, ya que trasciende la organización de datos simple y toma su propio idioma, capaz de comunicar algo sin el uso de las lenguas orales, como el portugués. Es en este contexto que se asemeja a la Lengua Brasileña de Señales (Libras), siendo susceptible de establecer la comunicación y la democratización de sus informaciones por medio de la lectura visual. Con eso, objetivamos discutir la relación semiótica entre la Libras y la cartografía, y presentar la versatilidad del lenguaje cartográfico en la comunicación de informaciones a alumnos sordos, y así contribuir con las estrategias de inclusión en la enseñanza escolar. Para ello, la metodología utilizada consistió en la aplicación de un taller de alfabetización cartográfica en una escuela de educación especial en Santa Maria, RS / Brasil, donde pudimos trabajar la lectura e interpretación de las informaciones presentadas en los mapas con los alumnos sordos. Los resultados mostraron respuestas positivas a la premisa inicial de que el lenguaje cartográfico es fácilmente comprendido por alumnos sordos, posibilitando de forma significativa la alfabetización cartográfica, y consecuentemente, la comprensión de los contenidos geográficos.

PALABRAS-CLAVE: Relaciones semióticas. Enseñanza de Geografía. Libras.

\section{INTRODUÇÃO}

O ensino de Geografia tem sofrido profundas transformações técnicas e metodológicas, em uma busca ininterrupta pelo aperfeiçoamento teórico e prático com vistas à ampliação de seu alcance enquanto ciência capaz de influenciar positivamente na formação dos sujeitos. Graças à constante evolução epistemológica, vemos surgir pesquisas geoeducacionais que buscam a compreensão dos conteúdos geográficos de forma democrática, independentemente das eventuais limitações físicas e/ou cognitivas dos educandos. Aspira-se a inserção cada vez maior de alunos de diferentes comunidades nas reflexões e propostas metodológicas de ensino, à estimular sua iniciativa e criticidade sobre o arranjo social presente, proporcionando e abrindo, de forma permanente, espaços de manifestação sobre seus anseios.

Dentre os mais variados conteúdos pertinentes ao ensino de Geografia está a Cartografia Escolar, matéria relevante à compreensão dos acontecimentos situados em territórios, capaz de contextualizar diferentes objetos de estudo geográfico através de representações planas, em diferentes escalas de aproximação. Em um momento da reflexão educacional em que se vem se discutindo assiduamente a inclusão dos alunos, a Cartografia Inclusiva revela-se um campo fecundo de contribuições. 
A inclusão por meio da Cartografia busca proporcionar aos alunos uma alfabetização cartográfica que faça uso de recursos adaptados às capacidades dos alunos, a exemplo dos sujeitos surdos e deficientes auditivos que fazem uso da língua brasileira de sinais. A Cartografia, nesse caso, não exige dos alunos o domínio da língua portuguesa, e embora seja necessário conhecer alguns conceitos cartográficos, as representações empregadas nessa área possibilitam leituras de evidente apelo didático.

A justificativa para a discussão do tema aqui apresentado se deve pelo intento de apresentar, sob novas perspectivas metodológicas, as contribuições do ensino de Geografia a uma educação cada vez mais inclusiva. Nesse sentido, identificamos a Cartografia Escolar como uma área cujos conteúdos contêm significativo potencial para a construção de estratégias didáticas voltadas aos alunos surdos. Isso se dá graças à sua linguagem baseada na transmissão de informações por meio de representações artísticas, passíveis de fácil leitura por parte dos alunos surdos. Assim, objetivamos discutir a relação semiótica entre a linguagem cartográfica e a língua brasileira de sinais (Libras), e destacar a versatilidade da Cartografia como meio de transmissão de informações e como estratégia de inclusão no ensino escolar.

Esta pesquisa foi realizada na Escola Estadual de Educação Especial Dr. Reinaldo Fernando Cóser (EEEE Cóser). A escola está localizada no Bairro Lorenzi, do Distrito Sede do município de Santa Maria, que se encontra na região central do estado do Rio Grande do Sul, no Brasil. A escola se diferencia pelo uso prioritário da Língua Brasileira de Sinais embora muitos alunos sejam alfabetizados paralelamente em português -, tanto na comunicação social, quanto no aprendizado das disciplinas escolares, traduzindo inclusive os livros didáticos do Programa Nacional do Livro Didático (PNLD), comuns a todo o sistema de ensino. Esta instituição de ensino atende alunos surdos e deficientes auditivos de diferentes municípios da região central do estado gaúcho, a exemplo de Itaara, Júlio de Castilhos, Tupanciretã e São Sepé.

\section{LEVANTAMENTO TEÓRICO}

Para discutirmos a relação entre a linguagem cartográfica e a língua brasileira de sinais é necessário compreender a estrutura cartográfica e a manifestação de sua linguagem que se apresenta através de códigos facilmente decifráveis aplicados às suas representações. Antes de qualquer aprofundamento epistemológico, é importante ter em conta que a Cartografia é um instrumento fundamental à aprendizagem geográfica. Conforme Castellar (2005, p. 216), a Cartografia é considerada uma linguagem por constituída como "[...] um sistema-código de comunicação imprescindível em todas as esferas da aprendizagem em Geografia, articulando fatos, conceitos e sistemas 
conceituais", permitindo ler e escrever as características do território em forma de representação. Nesse sentido, ela é uma opção metodológica pertinente em todos os conteúdos da Geografia, para identificar e conhecer não apenas a localização dos países, mas entender as relações entre eles e compreender os conflitos e a ocupação do espaço.

Sob uma perspectiva semelhante, Cavalcanti (2005, p. 88) escreve que a Geografia "[...] desenvolveu uma linguagem, um corpo conceitual, que acabou por constituir-se numa linguagem geográfica. Essa linguagem está permeada por conceitos que são requisitos para a análise dos fenômenos do ponto de vista geográfico". Vale ressaltar que tal linguagem geográfica, que possui características distintas de outras ciências, está diretamente vinculada a possibilidade de ler e interpretar o espaço por meio da Cartografia, ou seja, é a Cartografia a responsável por comunicar os acontecimentos no espaço. Para a autora, a Cartografia aparece não apenas como técnica ou tópico de conteúdo, mas como linguagem que apresenta códigos, símbolos e signos próprios. Essa linguagem deve ser apreendida pelo aluno "[...] para que ele possa se inserir no processo de comunicação representado pela Cartografia (uma ciência da transmissão gráfica da informação espacial) e desenvolver as habilidades fundamentais de leitor de mapas e de mapeador da realidade" (CAVALCANTI, 2005, p. 9).

Uma das características mais interessantes do uso da Cartografia como mediadora no processo de comunicação, especialmente para alunos surdos que não são alfabetizados em língua portuguesa, é a possibilidade de produzir entendimento sobre uma representação sem a necessidade de utilizar um termo específico para fornecer sentido à imagem, o que não significa que a compreensão do objeto pelo sujeito prescinda de significação. Nesse sentido, é fundamental destacar que a comunicação se realiza no ato de significação das imagens pelo sujeito, tanto para aquele que comunica quanto para o receptor. Logo, a linguagem que utiliza apenas de imagens visuais também é dependente de uma estrutura textual. Em Libras, essa textualização ocorre através dos sinais (por intermédio de classificadores, ou datilologia). O aluno surdo, por exemplo, pode ver uma bacia hidrográfica existente em uma carta topográfica, pode apreender suas particularidades, e ser capaz de reconhecer outras drenagens quando necessário. Porém, se durante a comunicação entre pessoas surdas não houver um termo que dê significado a esse elemento, (a imagem vista), não será possível comunicar sobre ele na ausência de uma imagem correspondente. Assim funciona com as línguas faladas: se você não tem uma palavra para o objeto, torna-se impossível falar sobre ele de forma independente de uma imagem.

A grande diferença no processo de aquisição de conhecimentos cartográficos entre alunos surdos e ouvintes está na forma como os alunos percebem os mapas. Com os alunos surdos, é comum iniciarmos a alfabetização de um modo diverso, fazendo uso dos mapas e depois esclarecendo sobre seus elementos constituintes enquanto que, para os 
alunos ouvintes, é comum iniciarmos a alfabetização pela base conceitual de cada um dos conteúdos presentes nos mapas, e posteriormente mostrando a sua aplicabilidade. Apesar de os processos de aquisição de conhecimentos cartográficos serem realizados de formas relativamente diferentes entre os alunos surdos e ouvintes, dadas as diferenças entre as modalidades sensoriais envolvidas em um e outro caso, é importante destacar que uma vez constituídos pelos alunos os significados próprios à alfabetização cartográfica, a leitura dos mapas ocorre de igual modo, primeiramente se vê as informações e então as decodifica, interpretando-as. É nesse sentido que identificamos na Cartografia um componente pedagógico profundamente democrático.

Nas aulas de Geografia para alunos surdos e deficientes auditivos é relevante considerar a importância do aprendizado mediado pela comunicação visual em Libras e o uso de recursos didático-pedagógicos como ferramentas para a compreensão dos conteúdos. Nesse sentido, a Cartografia Escolar assume um papel comunicativo de destaque entre alunos e conteúdos, apresentando de forma aplicada o modo pelo qual algumas informações podem ser organizadas em um mapa ou outra representação cartográfica.

Santana (2007, p. 80) informa que a língua combina dois modos distintos de significação: "o semiótico", que considera que o signo existe quando reconhecido como significante pelo conjunto dos membros da comunidade linguística; e "o semântico", engendrado pelo discurso e pela linguagem como produtora de mensagem que toma em seu encargo um conjunto de referentes. A língua é o único sistema que articula essas duas dimensões.

Fernandes e Correia (2010) afirmam que a capacidade humana de significação é uma competência específica para as operações, produção e codificação de signos, e que esta competência permite, em qualquer etapa, a produção de novos signos e suas combinações, não apenas para o processo de comunicação, mas também no processo cognitivo. Parte importante da leitura e interpretação de imagens, como os mapas, dependem da compreensão dos signos, muito valorizados em Geografia, uma vez que "[...] tratar do conceito de signo é fundamental para um estudo de desenvolvimento dos processos de significação, considerando as etapas de evolução cognitiva" (FERNANDES; CORREIA, 2010, p. 7). Os autores ainda explicam que na perspectiva psicolinguística a compreensão dos signos é a derivação do desenvolvimento das funções intelectuais dos indivíduos: atenção deliberada, memória, abstração, lógica e capacidade para comparar e diferenciar.

Os signos exercem uma função relevante na compreensão das representações expostas nos mapas, sejam temáticos ou sistemáticos, pois eles remetem à leitura dos símbolos empregados que mostram na linguagem cartográfica um significado específico. Nesse sentindo, Castellar (2005) explica que a criança vivencia o processo de letramento 
cartográfico ao compreender as noções, a forma de ler e de elaborar mapas mentais, experimentando atividades simbólicas como, por exemplo, entender o "[...] significado dos símbolos e signos que correspondem aos fenômenos que são representados nos desenhos e que estão relacionados e agrupados para que possa ser organizada uma legenda" (CASTELLAR, 2005, p. 215).

Vygostky (1989) afirma que o significado da palavra constitui um laço estreito do pensamento e da linguagem, e que se trata de um fenômeno da fala ou de um fenômeno do pensamento. Segundo o autor, "[...] uma palavra sem significado é um som vazio; o significado, portanto, é um critério da 'palavra', seu componente indispensável" (VYGOSTKY, 1989, 2005, p. 104). Ele afirma também que, do ponto de vista da psicologia, o significado de uma palavra é uma generalização ou um conceito, e como ambos são atos do pensamento, podemos considerar o significado como um fenômeno do pensar. Em consonância com as teorias dos processos mentais, Frawley escreve que "el habla es um lenguaje para el pensamiento, no um lenguaje del pensamiento"². (FRAWLEY, 1999, p. 124, grifo nosso, tradução nossa).

Segundo Santana (2007, p. 21), quando um pesquisador propõe determinadas abordagens para lidar com a surdez, é comum que não consiga ser totalmente imparcial em suas análises, pois sua proposta tende a refletir uma concepção particular da surdez, e tal concepção "[...] resulta do modo como cada estudioso encara a surdez, seja como deficiência, seja como diferença", o que está diretamente ligado à forma como o professorpesquisador interage com o aluno e, consequentemente, constrói a comunicação com ele.

É interessante a conceituação de Sassaki (1997) sobre a inclusão social como o processo pelo qual a sociedade se adapta para poder incluir, em seus sistemas gerais, pessoas com necessidades especiais, e a preparação dessas para assumir seus papéis na sociedade. A inclusão social constituir-se-ia em um processo bilateral no qual as pessoas (ainda excluídas), e a sociedade, procuram equacionar problemas, decidir sobre soluções e efetivar a equiparação de oportunidades para todos. Para Rodrigues, Stefanno e Corrêa (2017, p. 1),

[...] a inclusão escolar é um processo de aprendizado e aperfeiçoamento da educação. Nela os agentes modificam-se e se transformam em prol do desenvolvimento de habilidades e técnicas para que o conhecimento seja proporcionado coletivamente. Dentro da perspectiva de inclusão escolar, temos dentro da ciência geográfica o aprimoramento de uma de suas bases principais, a Cartografia, que tende a adaptar-se de forma inclusiva.

A partir das observações e atividades realizadas na escola Cóser, ficou fácil entender como a linguagem cartográfica se articula com a língua brasileira de sinais de forma a

\footnotetext{
2 "A fala é uma linguagem para o pensamento, não uma linguagem do pensamento".
} 
aproximar o ensino de Geografia aos alunos surdos e deficientes auditivos. A leitura visual é o cerne da questão, não simplesmente por ambas serem constituídas por imagens, mas em razão da interpretação apurada que os alunos surdos possuem, e pelo sistema código que ambas as formas de comunicação possuem.

\section{SISTEMA-CÓDIGO DA CARTOGRAFIA}

O sistema-código da Cartografia, em especial na área escolar, é constituído por signos, significante e significados. Os signos integram a própria gênese da linguagem, ou seja, são as unidades fundamentais para a compreensão de um código. Segundo Francischett (1997), um signo é um símbolo que se refere ao objeto, e que o denota através de uma associação de ideias gerais, operando no sentido de fazer com que o signo seja interpretado como se referindo àquele objeto representado. Para Pierce (2005), o signo é aquilo que, sob certo aspecto ou modo, representa algo para alguém. Dirige-se a alguém, isto é, cria na mente da pessoa um signo equivalente, ou talvez um signo mais desenvolvido. O significante é o elemento tangível, ou seja, perceptível ao sujeito, constituído como o veículo material do signo. Já o significado é aquilo que se atribui ao signo, é o conceito, o sentido, ou como o sujeito percebe e compreende subjetivamente aquilo que é apresentado por meio do signo.

Para Almeida e Passini (1994), a representação de um determinado espaço ao ser codificada pode ser chamada como um modelo de comunicação, valendo-se de um sistema semiótico complexo. A informação é transmitida através de uma linguagem cartográfica que se utiliza de três sistemas básicos: sistema de signos, redução e projeção. A Cartografia é decodificada por meio de legendas ou convenções cartográficas.

Segundo Lima (1992), a produção e o uso de mapas devem ser considerados como processos em que a informação geográfica se origina, é comunicada e produz efeitos. É nesse contexto estrutural que Souza e Katuta (2001, p. 51) abordam outra questão importante: o alfabeto cartográfico. Para os autores,

[...] ler mapas, como se fossem um texto escrito, ao contrário do que parece, não é uma atividade tão simples assim, para que isso ocorra, faz-se necessário aprender, além do alfabeto cartográfico, a leitura propriamente dita, entendida aqui não apenas como mera decodificação de símbolos. As noções, as habilidades e os conceitos de orientação e localização geográficas fazem parte de um conjunto de conhecimentos necessários, juntamente com muitos outros conceitos e informações, para que a leitura de mapas ocorra de forma que o aluno possa construir um entendimento geográfico da realidade. 
Para Santaella (1983, p. 1), a semiótica é "[...] o termo construído a partir da palavra grega semeion, e designa a filosofia das linguagens ou a ciência dos signos", a "ciência de toda e qualquer linguagem", que envolve conceitos importantes para entender a natureza do signo, da significação e da comunicação. Para Sirgado (1991, p. 41), "[...] os seres humanos criaram instrumentos e sistemas de signo, cujo uso lhes permite transformar e conhecer o mundo, comunicar suas experiências, e desenvolver novas funções psicológicas. A mediação dos sistemas de signos constitui o que denominamos mediação semiótica".

Para Vygostky (1989), os signos conduzem os indivíduos a uma estrutura específica de comportamentos, desde o desenvolvimento biológico até aos processos psicológicos. Tais apontamentos nos permitem evidenciar a afinidade potencial entre a língua brasileira de sinais e a linguagem cartográfica, uma vez que ambas se utilizam de uma estrutura visual composta por signos, e que desconsideram a necessidade da oralidade como fundamento relevante para o processo de comunicação.

Refletir sobre a relação entre a linguagem cartográfica e a Libras nos permite conhecer mais sobre as possibilidades da Cartografia Escolar, assim como contribuir para que possamos compreender melhor como os sujeitos surdos percebem as representações cartográficas e, por consequência, as informações do espaço representado, proporcionando a comunicação entre a Geografia e os alunos. Esse feito proporciona a reflexão acerca de diferentes metodologias para o ensino de Geografia em um contexto onde se prezam cada vez mais iniciativas que visem a educação inclusiva.

Diferentemente do que se imagina, e que por vezes se constitui como estereótipo, a língua brasileira de sinais não é apenas uma forma de expressar através das mãos o que se reproduz oralmente na língua portuguesa. A Libras é, em si, uma língua própria, onde a interpretação dos signos ultrapassa o simples uso de um termo, ela representa a forma como os sujeitos surdos entendem o mundo e como expressam seus pensamentos, além do reconhecimento de sua comunidade. Frente a isso, a Cartografia se torna um importante mediador entre os diversos conteúdos da Geografia para com a comunidade surda, o que aproxima as pessoas e busca estimular a criticidade por parte dos sujeitos, bem como a integração social.

Os muitos objetos da Geografia, como o espaço, o território, o lugar e a paisagem encontram na Cartografia um meio de expressão próprio a diferentes perspectivas e formas de apreensão. A experiência nos mostra que a alfabetização cartográfica é um caminho eficaz de formação de relações de significação com o mundo. A partir do mapa é possível introduzir o estudo de conceitos básicos como escala, legenda e orientação, entre outros. $O$ sujeito surdo ou deficiente auditivo encontra aí um campo fecundo para exercitar a intersubjetividade. 


\section{METODOLOGIA}

A Escola Estadual de Educação Especial Dr. Reinaldo Fernando Cóser localiza-se no Bairro Lorenzi (figura 1), na região sul do município de Santa Maria, e é uma instituição de referência ao atendimento de alunos surdos e deficientes auditivos. Segundo informações obtidas junto à $8^{\circ}$ Coordenadoria Regional de Educação $\left(8^{\circ} \mathrm{cre}\right)$, responsável pela administração das escolas estaduais da região central do RS, a escola Cóser possuía cerca 78 alunos matriculados no ano de 2017, sendo 34 surdos e 44 deficientes auditivos, das mais variadas idades, tanto na Educação Infantil quanto na Educação de Jovens e Adultos (EJA).

Figura 1 - Mapa de localização da escola Cóser

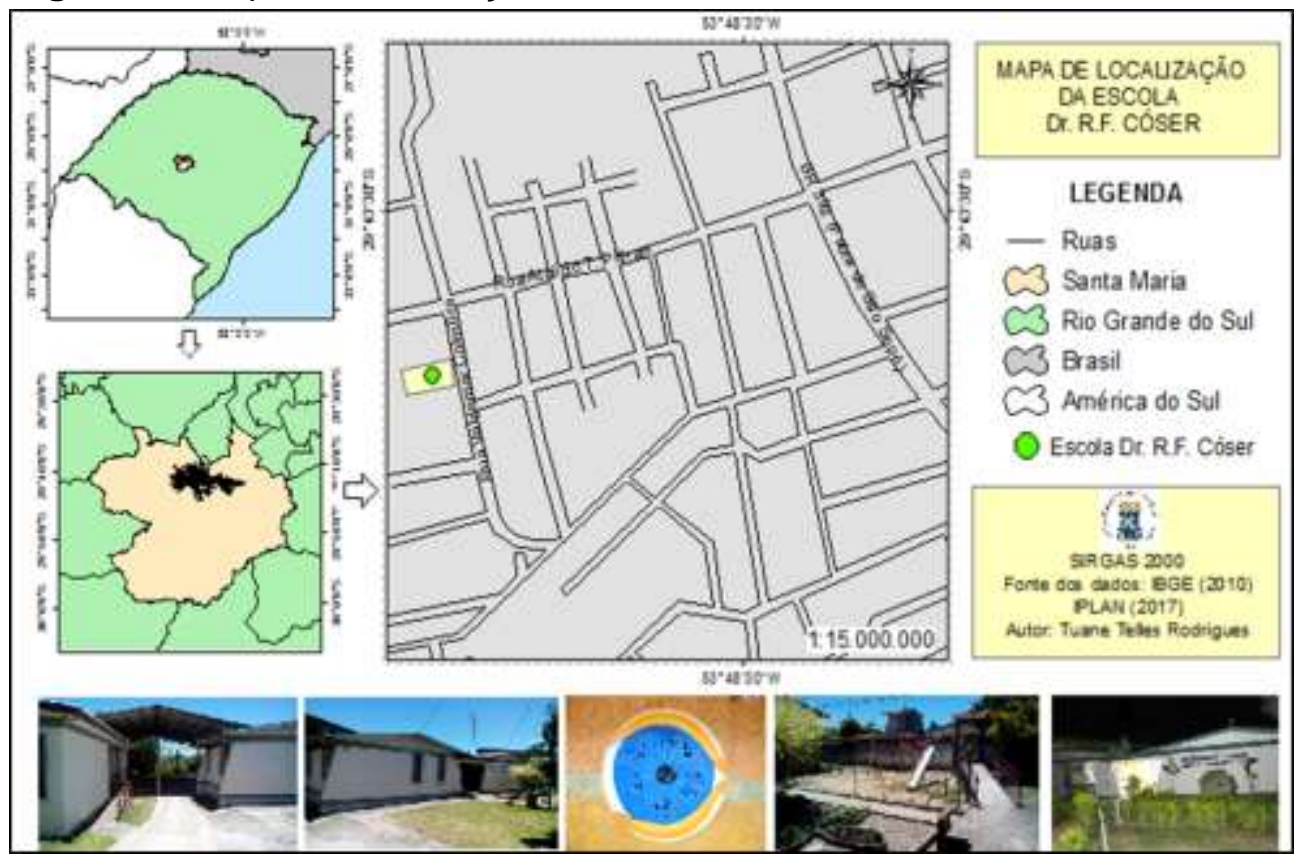

Fonte: Rodrigues (2019).

No mesmo período de coleta de dados, apenas mais uma escola do sistema estadual de ensino no município possuía um aluno surdo, a Escola Básica Estadual Cícero Barreto. Diante disso, é fácil imaginar a importância que a Escola Cóser possui para a comunidade surda da região, sendo esta a razão pela qual optamos em realizar a pesquisa na instituição. A escola também atende alunos com outras necessidades especiais, como autismo e deficiência intelectual, entre outras, graças ao acompanhamento especializado disponibilizado. É possível também realizar cursos de Libras, que são oferecidos gratuitamente para toda a comunidade de Santa Maria. Na primeira etapa da metodologia utilizada, em que realizamos a pesquisa teórica referente a Cartografia Escolar, educação especial e a estrutura da língua brasileira de sinais. 
Na segunda etapa realizamos uma oficina de alfabetização cartográfica com 12 alunos do ensino fundamental, sendo cinco do sexto ano, dois do sétimo e cinco do oitavo ano, para que pudéssemos compreender como os alunos interpretam a partir de uma leitura visual as representações cartográficas. Para isso, realizamos três encontros matinais (um para cada turma) no período de uma semana, nos quais pudemos realizar a exposição teórica dos conteúdos pertinentes à alfabetização cartográfica dos alunos com o auxílio da professora da classe, que realizou a simultânea tradução em Libras das informações que transmitimos de forma oral.

Antes da aplicação expositiva dos conteúdos, apresentamos um mapa e solicitamos que os alunos o lessem e o interpretassem, para obtermos um diagnóstico acerca da compreensão dos alunos por meio das imagens em uma etapa anterior a uma construção mais refinada dos conhecimentos cartográficos. Isso contribuiu também na forma de condução da exposição dos conteúdos, enfatizando alguns conceitos mais relevantes para um aprendizado significativo por parte dos alunos.

Os conteúdos trabalhados com as turmas foram aqueles elementos que compõem os mapas: escala, gráfica e numérica; orientação, pontos cardeais, colaterais; coordenadas, UTM e Geográficas; projeções, cônica, plana e cilíndrica; legenda e convenções cartográficas; título dos mapas; fonte dos dados e organização; e diferentes representações como cartas, mapas e plantas; entre outros. A apresentação se deu com o uso de um computador (aproximamos os alunos para ver a apresentação em slides, pois não havia disponível Datashow - figura 2). Utilizamos também outras ferramentas como mapas, a carta topográfica de Camobi (Folha SH.22-V-C.2; MI-2965/2; escala 1:50.000) e um globo.

Figura 2 - Realização da atividade com os alunos

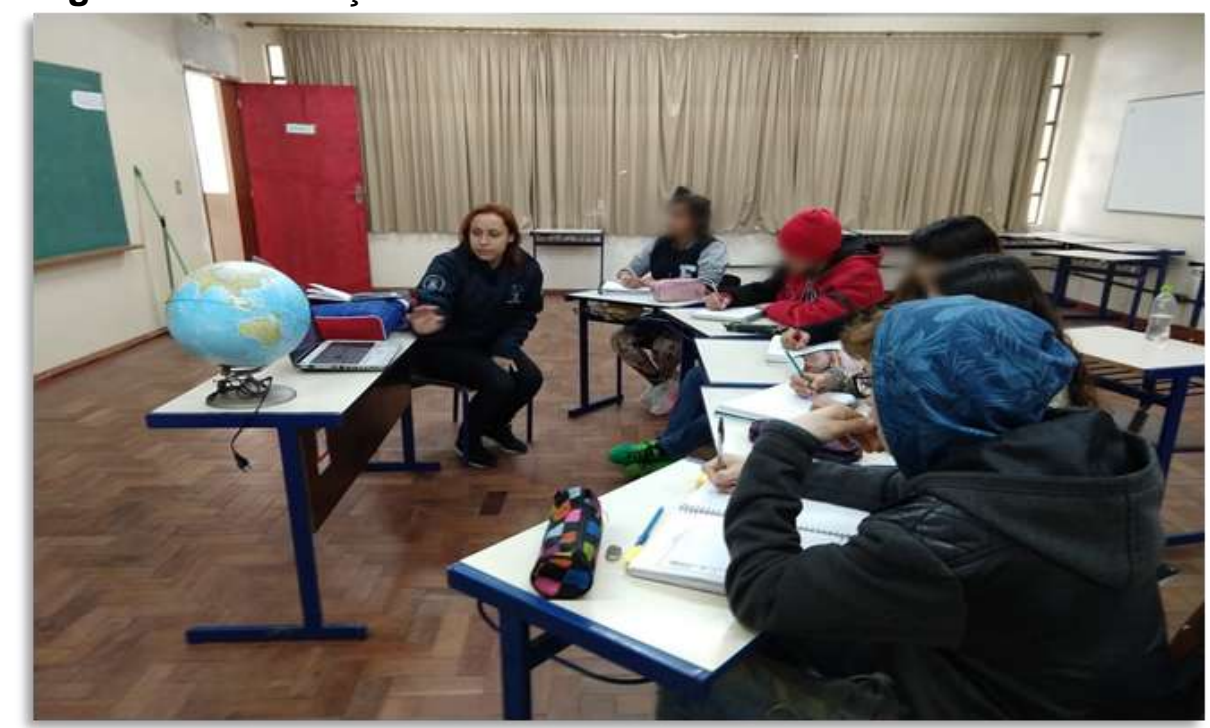

Fonte: autora (2018). 
Após a aplicação da oficina, aplicamos um questionário para colher percepções dos alunos sobre as representações. Tal instrumento de análise foi construído de forma simples, com uma escrita objetiva, pois muitos alunos não possuíam domínio da língua portuguesa, de modo que foi necessário, inclusive, dar explicações adicionais aos alunos sobre algumas das questões. O quadro 1, apresentado a seguir, expõe as perguntas utilizadas no questionário.

Quadro 1 - Questionário utilizado na oficina pedagógica

\begin{tabular}{|l|l|l|l|}
\hline \multicolumn{1}{|c|}{ Sim } & \multicolumn{1}{|c|}{ Não } & \multicolumn{1}{c|}{ Parcialmente } \\
\hline 1- $\begin{array}{l}\text { Você conseguiu descobrir qual território foi representado } \\
\text { no mapa? }\end{array}$ & & \\
\hline 2- $\begin{array}{l}\text { Você conseguiu compreender a distribuição das } \\
\text { informações a partir do tema apresentado no mapa. }\end{array}$ & & \\
\hline 3- $\begin{array}{l}\text { Você consegue perceber qual e onde está a escala no } \\
\text { mapa? }\end{array}$ & & \\
\hline 4- Você consegue encontrar a orientação no mapa? & & \\
\hline 5- $\begin{array}{l}\text { Você consegue dizer quais números referem-se às } \\
\text { coordenadas no mapa? }\end{array}$ & & \\
\hline
\end{tabular}

Fonte: autora (2019).

\section{RESULTADO E DISCUSSÃO}

Os resultados obtidos mostraram que a Cartografia Escolar é de fato uma ferramenta importante para a inclusão de alunos surdos e deficientes auditivos no ensino de Geografia. Essa conclusão se deve à leitura e à interpretação que os alunos fizeram sobre o mapa da vegetação brasileira, apresentado no começo da oficina pedagógica.

A relação de proximidade potencial entre a linguagem cartográfica e a língua brasileira de sinais ficou evidente, pois a construção de sinais utilizados pelos alunos, e até mesmo pela professora, teve como base o que era observado nos mapas, como as coordenadas e as escalas, entre outros aspectos. Dessa forma, os alunos tenderam a compreender o significado de uma representação cartográfica mesmo que não tivessem disponível uma palavra específica para ela. Conseguiram entender algumas relações entre os espaços reais e as suas representações gráficas.

Analisando os resultados obtidos por meio do questionário aplicado ao final da aula expositiva, tivemos a confirmação de que os alunos conseguem entender os conteúdos pertinentes ao ensino de Geografia por meio da contextualização adequada que os mapas possibilitam. Na pergunta número 1, que questionou sobre qual parcela do território estava representado no mapa, dez alunos marcaram "sim", ou seja, que conseguiram entender a informação que o mapa transmitiu. Os outros dois alunos compreenderam parcialmente o conteúdo, e essa dificuldade se deu em razão da não compreensão do título do mapa, 
expresso em língua portuguesa. Na questão seguinte, os doze alunos afirmaram conseguir compreender a distribuição das informações espacializadas no território brasileiro. Isso se atribuiu à organização das informações, assim como ao uso harmonioso de cores, e ao tamanho do mapa.

Quando questionados sobre a identificação da escala, todos os alunos responderam positivamente. Contudo, isso não significou que os alunos conseguissem utilizar a escala de forma prática, ou seja, de que eram capazes de estabelecer a devida relação numérica entre o espaço real e a representação, tampouco de que conseguissem calcular o valor escalar. Segundo a professora da turma, esse é um dos conteúdos mais complexos de ensinar aos alunos, principalmente porque muitos sinais utilizados são improvisados durante as aulas, por não haver na língua brasileira de sinais um acordo nacional sobre como sinalizar determinados conteúdos, sendo necessário, neste caso, o uso de datilologia.

A questão número 4 buscou saber se os alunos conseguiram identificar a orientação no mapa com o objetivo de evidenciar se eles eram capazes de localizar esta informação na imagem, para que pudéssemos introduzir os pontos cardeais, colaterais e sub-colaterais, apresentando também os "três nortes" que aparecem nas cartas topográficas: o magnético, o geográfico e o da quadrícula. Todos os doze alunos conseguiram localizar, e com isso pudemos aprofundar a discussão.

"Você consegue dizer quais números referem-se às coordenadas no mapa?" foi a questão 5 do questionário. Com ela, pudemos iniciar uma das discussões mais complexas: a variabilidade das coordenadas nos mapas, suas funções e formas de localizar pontos sobre a superfície terrestre, apresentando as coordenadas geográficas e UTM. A esta questão, nove alunos afirmaram conseguir localizar no mapa, e os outros três tiveram dificuldades em um primeiro momento, devido à distância entre os valores apresentados no mapa.

Parte das dificuldades em localizar as informações nas representações cartográficas se dava pela escolha artística envolvida na composição dos mesmos, ou a qualidade da impressão. Isso ficou evidente frente à alta capacidade de percepção visual que os alunos surdos e deficientes auditivos dispõem, pois muitos eram capazes de perceber pequenos detalhes nos mapas, como falhas no desenho, ou pequenas interrupções nos GIF's utilizados durante a apresentação de slides.

Assim, graças a essa atividade, foi possível obter respostas positivas à premissa inicial, de que a linguagem cartográfica é facilmente compreendida por alunos surdos, possibilitando de forma significativa a alfabetização cartográfica, e consequentemente, a compreensão dos conteúdos geográficos. 


\section{CONSIDERAÇÕES FINAIS}

Este artigo buscou a compreensão de algumas relações entre a linguagem cartográfica e a língua brasileira de sinais, como forma de averiguar e refletir sobre a capacidade metodológica inclusiva que o ensino de Geografia possui. Ficou claro que a alfabetização cartográfica tende a ser uma das etapas mais importantes nesse processo. Sua relevância está em sua natureza, características que fazem da cartografia uma linguagem capaz de ser compreendida por alunos com ou sem necessidades especiais como a surdez e a deficiência auditiva. Com isso, a Cartografia Escolar pode ser, e de fato se torna um apropriado veículo de comunicação entre a Geografia, os alunos e a sociedade.

Muitas pesquisas voltadas à Cartografia Inclusiva têm sido desenvolvidas pelos laboratórios, que buscam novos recursos de acesso à informação pelos alunos, a exemplo da Cartografia Tátil, voltada para alunos cegos, e o jogo CartoCon, desenvolvido por Rodrigues (2019), que buscou a alfabetização cartográfica de alunos surdos e deficientes auditivos em Santa Maria/RS. O presente artigo buscou colaborar com a discussão sobre o ensino de Geografia e a sua acessibilidade.

A educação inclusiva deve considerar as transformações dos meios de comunicação e entretenimento e utilizar suas linguagens a seu favor. A comunicação é o locus central desse processo e o contexto de atuação privilegiada do educador. Nela devem operar os esforços de integração e valorização das diferentes experiências. Democratizar a educação é, assim, não apenas a introdução de um conceito político-liberal nos modos de gestão da instituição escolar. É torná-la efetivamente um espaço de convivência capaz não apenas de reproduzir, mas de alterar relações sociais.

A inclusão escolar é parte necessária de um tempo em que a sociedade toma consciência, além de seu dever solidário, de que o aprendizado também está no convívio e na experiência, com o amadurecimento das teorias e técnicas de aprendizado. Nesse sentido, acreditamos que dentro da perspectiva da inclusão na escola existem carências que precisam urgentemente de atenção e de soluções imediatas no modelo proposto para a educação, necessitando-se de ações que democratizem as mais variadas áreas do conhecimento e trazendo os alunos às novas dinâmicas de um mundo informatizado. É preciso estimular a integração das teorias e modelos práticos com mediações contemporâneas, fazendo uso das tecnologias voltadas para a educação. A Cartografia Inclusiva assume um papel importante na educação geográfica, e é através dela que muitos temas podem ser acessíveis aos educandos com necessidades especiais. Na medida em que as experiências fizerem parte do cotidiano, veremos o aperfeiçoar de teorias e métodos, não apenas na Geografia, mas também em outras áreas do conhecimento. É importante para o sujeito compreender o espaço em que vive nas mais diferentes escalas. Neste 
sentido, devemos mostrar-lhe o mundo, utilizando e respeitando suas experiências e limites, sejam sensoriais ou cognitivos. Portanto, é direito do educando o acesso ao mundo espacializado, seja em um mapa, uma maquete ou na interface digital, assim como lhe é fundamental compreender as dinâmicas que o rodeiam, o que corresponde ao dever do professor de lhe mostrar o caminho, não apenas através de recursos simples, mas também o ambientando ao mundo técnico e informatizado em que vivemos, tornando-o independente e autônomo, consciente de seus direitos e deveres de cidadão.

\section{REFERÊNCIAS}

ALMEIDA, R. D. de; PASSINI, E. Y. O espaço geográfico: ensino e representação. São Paulo: Contexto, 1994.

CASTELLAR, S. M. V. Educação geográfica:a psicogenética e o conhecimento escolar. Cadernos CEDES, Campinas, v. 25, n. 66, p. 209-225, 2005.

CAVALCANTI, L. de S. Cotidiano, mediação pedagógica e formação de conceitos: uma contribuição de Vygotsky ao ensino de Geografia. Cadernos CEDES, Campinas v. 25 n. 66, p. 185-207, 2005.

FERNANDES, E.; CORREIA, M. de C. Bilinguismo e surdez: a evolução dos conceitos no domínio da linguagem. In: FERNANDES, E. Surdez e Bilinguismo. Porto Alegre: Mediação, 2010. p. 6-22.

FRANCISCHETT, M. N. A cartografia como um sistema de signos. Revista Faz Ciência, Francisco Beltrão, v. 1, n. 1, p. 67 - 74, jan. 1997. Disponível em: http://erevista.unioeste.br/index.php/fazciencia/issue/view/471. Acesso em: 8 jul. 2019.

FRAWLEY, W. Vygostsky y la ciencia cognitiva. Barcelona: Paidós, 1999.

IBGE.Mapas. Bases e referenciais: bases cartográficas: cartas. Disponível em: https://mapas.ibge.gov.br/bases-e-referenciais/bases-cartograficas/cartas.html. Acesso em: 03 dez. 2017.

INSTITUTO DE PLANEJAMENTO DE SANTA MARIA - IPLAN. Mapas de Santa Maria. Disponível em: http://iplan.santamaria.rs.gov.br/site/home/pagina/id/140. Acesso em: 09 mar. 2019.

LIMA, S. T. Análise crítica das representações cartográficas nos livros didáticos de $1^{\circ}$ e $2^{\circ}$ graus. Boletim Paulista de Geografia, São Paulo, n. 70, p. 53-64, 1992.

PIERCE, C. S. Semiótica. São Paulo: Perspectiva, 2005.

RODRIGUES, T. T. O jogo digital como recurso didático na alfabetização cartográfica de alunos surdos e deficientes auditivos em Santa Maria, RS/Brasil. 2019. Dissertação (Mestrado em Geografia) - Universidade Federal de Santa Maria, Santa Maria, RS, 2019.

RODRIGUES, T. T.; STEFANNO, C.; CORRÊA, L. R. A cartografia inclusiva e o futuro no ensino da geografia. In: CONGRESSO INTERNACIONAL DE EDUCAÇÃO, 7., 2017, Santa Maria, RS. Anais... Santa Maria, RS: FAPAS, 2017. v. 7, p. 1-8. Tema: Educação Humanizadora: Valorizando a Vida na Sociedade Contemporânea. Disponível em: http://br60.teste.website/ fapas413/ index.php/anaiscongressoie/article/view/943. Acesso em: 8 jul. 2019.

SANTAELLA, L. O que é semiótica. São Paulo: Brasiliense, 1983.

SANTANA, A. P. Surdez e linguagem: aspectos e implicações neolinguísticas. São Paulo: Plexus, 2007. 
SASSAKI, R. K. Inclusão: construindo uma sociedade para todos. Rio de Janeiro: WVA, 1997.

SIRGADO, A. P. O conceito de mediação semiótica em Vygostky e seu papel na explicação do psiquismo humano. Cadernos CEDES, Campinas, SP, n. 24, p.38-51, 1991.

SOUZA, J. G. de; KATUTA, Â. M. Geografia e conhecimentos cartográficos: a cartografia no movimento de renovação da geografia brasileira e a importância do uso de mapas. São Paulo: UNESP, 2001.

VYGOSTKY, L. S. Pensamento e linguagem. São Paulo: Martins Fontes, 1989.

Recebido: março de 2019. Aceito: julho de 2019.

\footnotetext{
' Este artigo integra parte da discussão realizada na pesquisa de mestrado intitulada "O jogo digital como recurso didático na alfabetização cartográfica de alunos surdos e deficientes auditivos em Santa Maria/RS, Brasil", realizada no Programa de Pós-graduação em Geografia (PPGGeo), da Universidade Federal de Santa Maria (UFSM).
} 